\title{
Polycyclic aromatic hydrocarbons (PAHs) and mutagenicity in air emissions from the two-stage incineration of polystyrene with various metallic salt additives
}

\author{
Jiann-Hwa You ${ }^{\mathrm{a}, *}$, Pen-Chi Chiang ${ }^{\mathrm{b}}$, Shenq-Chyi Chang ${ }^{\mathrm{c}}$, \\ S. Wang-Wuu ${ }^{\mathrm{c}}$ \\ a Department of Chemical Engineering, Chang Gung College of Medicine and Technology, \\ Taoyuan, Taiwan, ROC \\ ${ }^{\mathrm{b}}$ Graduate Institute of Environmental Engineering, National Taiwan University, Taipei, Taiwan, ROC \\ ${ }^{\mathrm{c}}$ Department of Biochemistry, National Yang-Ming University, Taipei, Taiwan, ROC
}

Received 16 May 1995; accepted 28 August 1995

\begin{abstract}
The yield of 14 PAHs and soots were more with $\mathrm{BaCl}_{2}$ or $\mathrm{NaCl}$ additive than those without metallic chloride additives. This indicated that metallic chloride additives could promote the reaction sequence towards the growth and coagulation reaction of soots from PS pyrolysis. When the second-stage temperature increased to the critical temperature, black tar formed and the concentration of 14 PAHs was $10 \mu \mathrm{g} / \mathrm{g}$ PS. Pha, Flu and Pyr were major species found among the 14 PAHs. Log $K$ values, the ratios between the PAHs in gas phase and the PAHs in solid phases (per particulates weight; $1 / \mathrm{mg}$ ) increased as the stage-two pyrolysis temperature increased. When the stage-two incineration system was controlled at $900^{\circ} \mathrm{C}$ as were various oxygen supplies, the maximum value of $\log K$ occurred at $0.0525 \mathrm{O}_{2}(\mathrm{nl} / \mathrm{min})$ and $\log K$ value decreased as the oxygen supply increased. When oxygen supply was increased from 0 to $0.210 \mathrm{nl} / \mathrm{min}$, the mutagenicity of particulates extracts from the PS incineration with metallic chloride additives was still more stronger.
\end{abstract}

Keywords: PAHs; Mutagenicity; Incineration; Polystyrene; Air emission

\section{Introduction}

With the increase in environmental consciousness among the people, traditional solid-waste handling methods, landfill and incineration, are meeting with increasing public resistance. Especially, air emissions from incineration are now releasing not only traditional air pollutants, but also air toxics, such as polycyclic aromatic compounds (PAHs), dioxins, and furans.

\footnotetext{
* Corresponding author.
} 
PAHs, which are thought to be the precursors of soots and have also been known to be mutagenic or carcinogenic, after being metabolized, are commonly produced from the incomplete combustion processes [1-6]. The formation of PAHs and soot particulates in the incineration of organic compounds not only depends on temperature, residence time and oxygen supply, but also depends on additives, e.g. $\mathrm{Cl}_{2}$ and metallic salts. Since complex mechanisms are involved in the incineration (or combustion) processes, their influence on PAHs and soot particulates formation is not yet clearly understood and various hypotheses, such as ionic chemical mechanisms, hydroxyl radical equilibrium and electrostatic effects are proposed based on various experimental systems and results [7-13].

Dependence of PAHs-induced mutagenicity on the bay region of the molecule and on the activating cytochrome P-450 enzyme has already been studied [14]. The results showed that the mutagenic activity of PAHs without a bay region was largely independent of the source of activating enzyme. Some researchers indicated that nucleophilic epoxides were formed from a metabolic oxidation of PAHs and then the epoxide ring would react with a nucleophilic group in celluar DNA. With its DNA thus altered, the cell was unable to reproduce normally [15]. According to the experimental results of a prototype/laboratory-scale rotary kiln under suboptimal operation conditions, Demarini suggested that the mutagenic emission factors may depend as much as or more on the operating conditions of the incinerator than on the feed stock [16].

The objectives of this research work are to investigate the mutagenicity and PAHs in air emissions from the incineration of polystyrene with various metallic salt additives under various stage-two pyrolysis temperatures and oxygen supplies.

\section{Materials and methods}

Polystyrene (PS) (0.2 g) was incinerated at various temperatures and oxygen supplies in a two-stage incinerator. The two-stage incinerator consisted of two furnaces and two quartz tubes $(D=3 \mathrm{~cm}, L=30 \mathrm{~cm}$ and $L=50 \mathrm{~cm})$. The feed gas, which consisted of oxygen and nitrogen, was first introduced through two tubes ( $D=5.0 \mathrm{~cm}, L=30 \mathrm{~cm}$ ) containing $1 \mathrm{M} \mathrm{BaCl}_{2}$ or $3 \mathrm{M} \mathrm{NaCl}$ solution, and then carried $\mathrm{BaCl}_{2}\left(1.3 \times 10^{6} \mathrm{mmol} / \mathrm{s}\right)$ or $\mathrm{NaCl}\left(1.1 \times 10^{5} \mathrm{mmol} / \mathrm{s}\right)$ into the second-stage incinerator. The feed rate was controlled at $2.0 \mathrm{nl} / \mathrm{min}$ and at various oxygen ratios by using the flotation flowmeter and needle valves. The rate of temperature increase in the stage-one incinerator was controlled at $35-40^{\circ} \mathrm{C} / \mathrm{min}$, and the maximum temperature was controlled at $500^{\circ} \mathrm{C}$. The temperature in the stage-two incinerator was controlled at $700^{\circ} \mathrm{C}$ to $1200^{\circ} \mathrm{C}$. The theoretical residence time was $2-4 \mathrm{~s}$.

The glass-fiber filter was used for sampling the particulates and PAHs which were defined in the solid phase. PUF (polyurethane foam) was used for sampling the PAHs which were defined in the gas phase. The sampling time was $5 \mathrm{~min}$ and the sampling flow time was $5 \mathrm{nl} / \mathrm{min}$. The samples were pretreated in a series process: extraction, concentration and purification. Then the GC/MS (HP5890-11, HP G1034C MS Chemistation; NIST/EPA/NIH Mass Spectral Database-Envelop) 


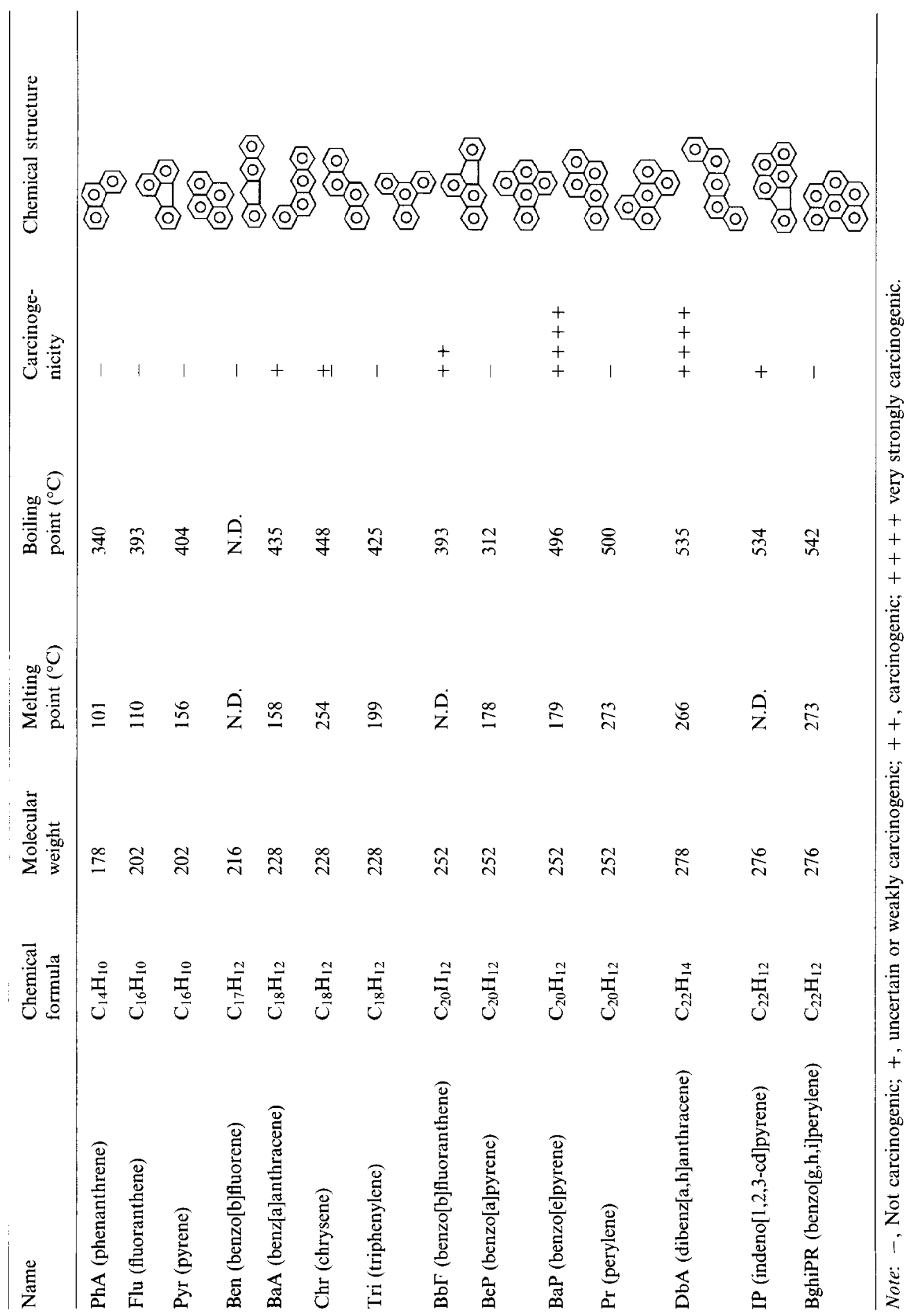


Table 2

The regression equations of GC/MS calibration curves of 14 PAHs

\begin{tabular}{lll}
\hline PAII & Regression equation & $R^{2}$ \\
\hline 1. PhA & $y=2.551 \times 10^{8} x+1.362 \times 10^{5}$ & 0.984 \\
2. Flu & $y=4.753 \times 10^{8} x+3.511 \times 10^{4}$ & 0.984 \\
3. Pyr & $y=2.793 \times 10^{8} x-2.314 \times 10^{4}$ & 0.996 \\
4. Ben & $y=1.095 \times 10^{8} x-4.005 \times 10^{5}$ & 0.998 \\
5. BaA & $y=1.700 \times 10^{8} x-1.681 \times 10^{5}$ & 0.990 \\
6. Tri + Chr & $y=5.208 \times 10^{8} x-1.532 \times 10^{5}$ & 0.999 \\
7. BbF & $y=1.818 \times 10^{8} x-1.078 \times 10^{5}$ & 0.998 \\
8. BeP & $y=1.647 \times 10^{8} x-6.384 \times 10^{5}$ & 0.999 \\
9. BaP & $y=3.363 \times 10^{8} x-3.876 \times 10^{5}$ & 0.997 \\
10. Pr & $y=1.759 \times 10^{8} x$ & $5.394 \times 10^{4}$ \\
11. IP & $y=2.141 \times 10^{8} x-2.451 \times 10^{5}$ & 0.999 \\
12. BghiPr & $y=2.310 \times 10^{8} x-1.001 \times 10^{5}$ & 0.999 \\
13. DbA & $y=1.214 \times 10^{8} x-1.592 \times 10^{5}$ & 0.992 \\
\hline
\end{tabular}

Note: (1) $y$, signal area; $x$ : PAHs(ug).

(2) $R^{2}$, correlation coefficient.

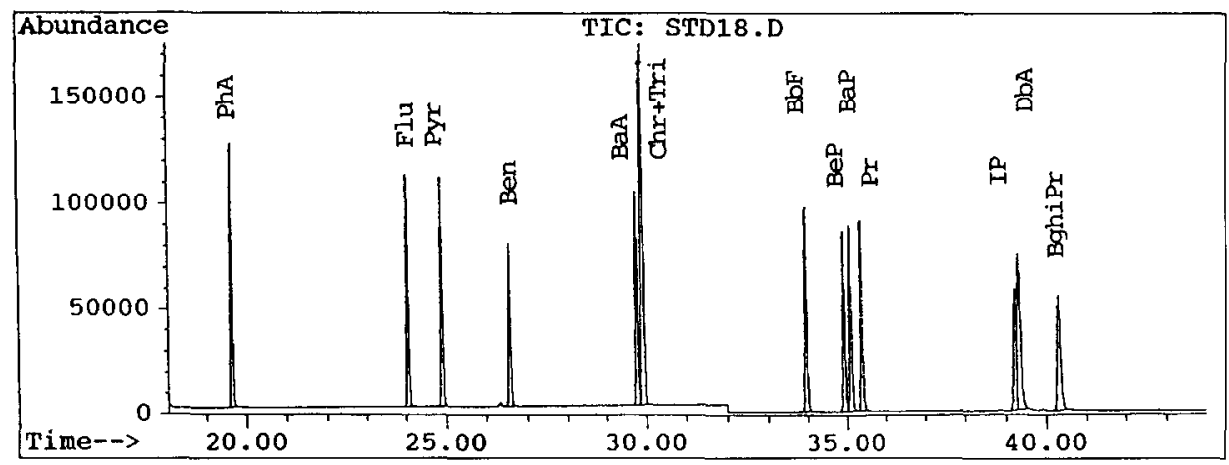

Fig. 1. GC/MS spectrum of 14 PAHs standards.

was used to analyze the 14 species of PAHs as shown in Tables 1, 2 and Fig. 1. During the extraction process, samples were placed and extracted in a soxhlet extractor with $250 \mathrm{ml}$ of dichlormethane at $40^{\circ} \mathrm{C}$ for about $16 \mathrm{~h}$. After the extraction process, the dichloromethane residue was concentrated to $1-2 \mathrm{ml}$ by using a rotary evaporator. The extract residue was purified with $100 \mathrm{ml}$ of hexane-dichloromethane $(7: 3, \mathrm{v} / \mathrm{v})$ in the tube purifier $(D=1 \mathrm{~cm}, L=20 \mathrm{~cm})$ which was packed with $2 \mathrm{~g}$ of activated aluminum and $3 \mathrm{~g}$ of silica gel. Finally, the purified samples were concentrated to $2 \mathrm{ml}$ by using a rotary evaporator, and dried to $1 \mathrm{ml}$ by using nitrogen.

The mutagenic activity of the particulates and PUF extracts were tested by the Ames Salmonella/microsomal assay system [17,18]. From the mutagenicity research of ambient particles, it was noted that the mutagenic response of strain TA98, which was used to detect frame-shift substitution mutation, was significantly higher than that of strain TA100, which was used to detect base-pair 
substitution mutation, upon incubation with the dichloromethane extract residue of airborne particulates. Thus, Salmonella typhimurim strain TA98 was employed to carry out the mutagenicity test in this study.

$0.8 \mathrm{ml}$ of DMSO was added to the dried sample in the vial. The aliquot of sample extracts in DMSO was placed in a test tube containing $2 \mathrm{ml}$ of molten top agar supplemented with a $0.1 \mathrm{ml}$ test solution, $0.1 \mathrm{ml}$ of an overnight broth culture of the tester strain, and with or without $0.5 \mathrm{ml}$ of $\mathrm{S} 9$ mixture. The $\mathrm{S} 9$ homogenate was prepared from the liver of Sprague-Dawley male rats pretreated for 5 days with Aroclor $1254(500 \mathrm{mg} / \mathrm{kg}$ body weight $)$ according to Maron and Ames et al. [17]. After 2 days incubation of the culture plates at $37^{\circ} \mathrm{C}$, histidine revertants of TA98 were scored.

\section{Results and discussion}

In our investigation, when the thermal temperature of the first-stage incinerator was at $350-450^{\circ} \mathrm{C}$, polystyrene was decomposed by the mechanisms of randomchain scission and end-chain scission. The long chain of polymer structure was broken down to a shorter-chain structure, i.e., styrene monomer, dimer, trimer and toluene.

When the intermediate products from the first-stage incinerator were introduced to the second-stage incinerator, the intermediate products should be transformed by two reactions, cracking and addition reactions. The cracking reaction occurred dominantly at $500-700^{\circ} \mathrm{C}$ in the second-stage incinerator. When the incineration temperature was greater than $1200^{\circ} \mathrm{C}$, the addition reaction occurred dominantly and the major products were soots which are more thermally stable.

The analysis results in the 14 PAHs, as shown in Fig. 2, indicated that the critical temperature for the maximum yield of $14 \mathrm{P} \Lambda \mathrm{Hs}$ was shifted from $1000^{\circ} \mathrm{C}$ to $900^{\circ} \mathrm{C}$, when metallic chloride $\left(\mathrm{BaCl}_{2}\right.$ or $\left.\mathrm{NaCl}\right)$ was added to the incineration system. The yields of $14 \mathrm{PAHs}$ and soots were more with $\mathrm{BaCl}_{2}$ or $\mathrm{NaCl}$ additive than those without metallic chloride additives. This indicated that metallic chloride additives could promote the reaction sequence towards the growth and coagulation reaction of soots from PS pyrolysis. When the second-stage temperature increased to the critical temperature, black tar formed and the concentration of 14 PAHs was $10^{4}-10^{5} \mu \mathrm{g} / \mathrm{g}$ PS. Pha, Flu and Pyr were major species found among the 14 PAHs, as shown in Fig. 3. When the stage-two temperature was increased, the concentration of the $14 \mathrm{P} \Lambda \mathrm{Hs}$ formed was decreased. The reason was that the thermal temperature provided enough energy for the low-ring PAHs to grow to high-ring PAHs and soot particulates. At incineration temperature above $1000^{\circ} \mathrm{C}$, the soot particulates of black powder formed and the weight of soot particulates formed increased as the stage-two pyrolysis temperature increased.

The above results also indicated that PAHs would effectively react with phenyl, biphenyl, naphthyl, binaphthyl, and $\mathrm{C}_{2} \mathrm{H}_{2}$ and grew to larger PAHs when the pyrolysis temperature was increased to a higher temperature of $1000^{\circ} \mathrm{C}$. Reactions of soot formation such as nucleation, condensation coagulation, aggregation mechanisms 


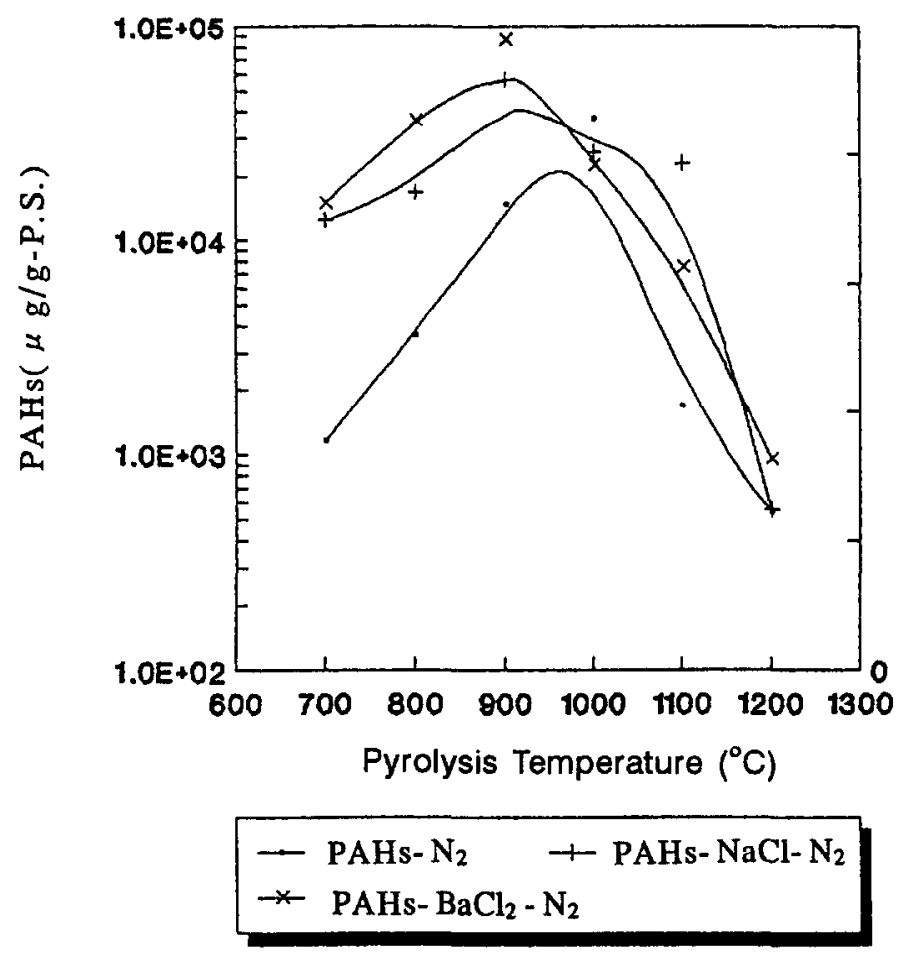

Fig. 2. Formation of 14 PAHs from polystyrene incineration with or without metallic chloride additives under various pyrolysis temperatures.

occurred effectively. Since the change in free energies caused by the series reactions of PAHs and soot formation was so large, reactions became practically irreversible. This, in turn, had the effect "of pulling" the reaction sequence forward towards formation of larger PAHs and soot particles. It has been postulated that mechanism for coagulation is through the reactions of aryl radical $+\mathrm{PAH}$, and molecule and soot active site + soot [10].

Of the 14 species of PAHs, only Pha, Flu and Pyr were always found to be in the gas phase in the PUF sample. The reason may be that the boiling points and vapor pressures were low. The various distributions of 14 PAHs between the gas and solid phases resulting from the polystyrene incineration with or without metallic chloride additives were caused by various tempcratures and oxygen supplies. The Pha, Flu and Pyr distributions between the solid and gas phases at various pyrolysis temperatures are shown in Fig. 4 and the relationship can be expressed as

$$
\log K=-A / T+B \text {, }
$$

where $K=\mathrm{PAH}_{(\mathrm{gas})} /\left(\mathrm{PAH}_{\text {(solid) }} /\right.$ particulates), $T$ is the temperature of the secondstage incinerator $(\mathrm{K})$ and $A, B$ are constants.

Log $K$ values, the ratios between the PAHs in gas phase and the PAHs in solid phases (per particulates weight; $1 / \mathrm{mg}$ ) increased as the stage-two pyrolysis 


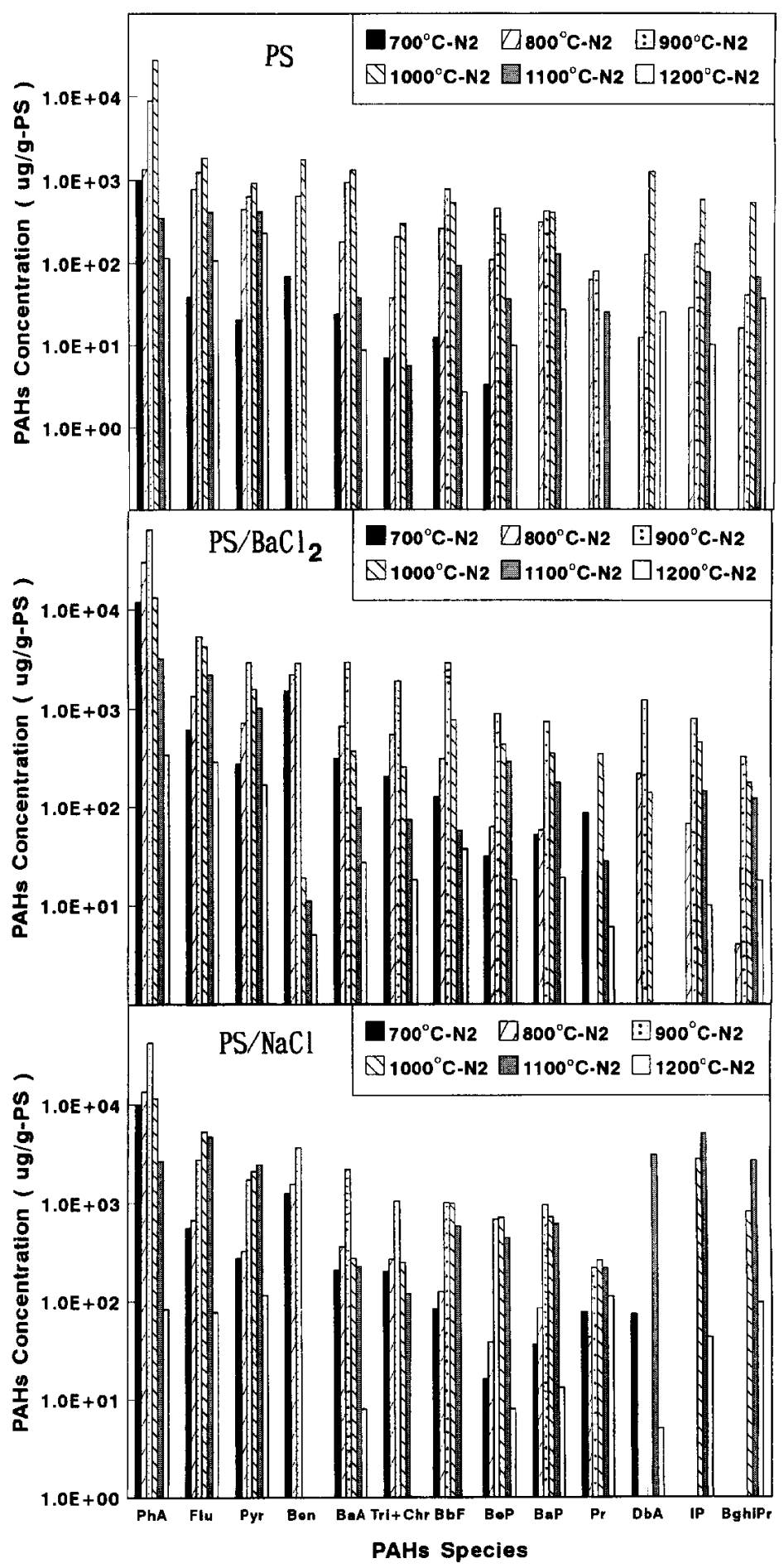

Fig. 3. Formation of $14 \mathrm{PAHs}$ species during polystyrene incineration under various metallic chloride additives and various pyrolysis temperatures. 


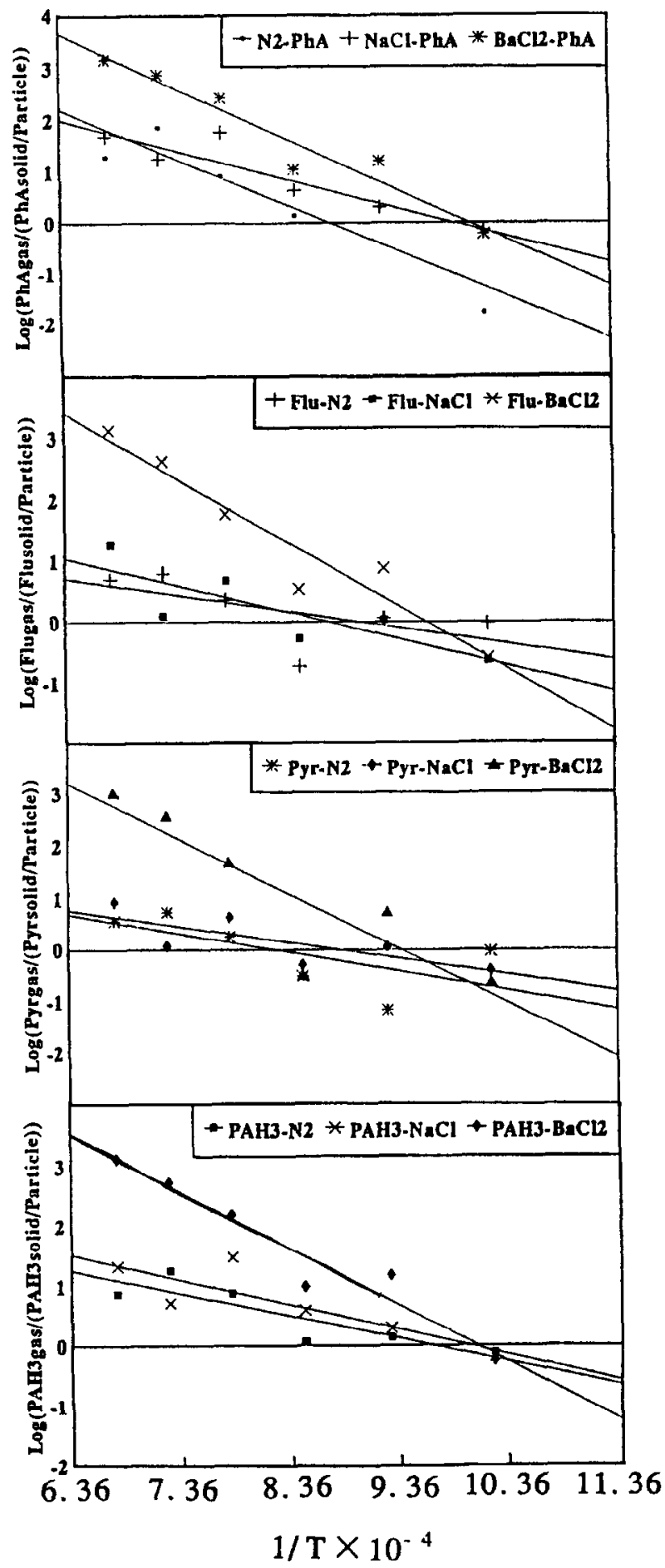

Fig. 4. The PAHs distributions between the solid and gas phases in air emissions from polystyrene incineration at various pyrolysis temperatures. 
Table 3

The distribution constants of PhA, Flu, and Pyr between the gas and solid phases

\begin{tabular}{lllll}
\hline Materials & Species & $A$ & $B$ & $R^{2}$ \\
\hline PS & PhA & 8882.5 & 7.9 & 0.836 \\
& Flu & 2604.4 & 2.4 & 0.371 \\
& Pyr & 3612.3 & 3.0 & 0.471 \\
& PAH $_{3}$ & 3760.6 & 3.7 & 0.770 \\
PS $+\mathrm{BaCl}_{2}$ & PhA & 9658.8 & 9.8 & 0.939 \\
& Flu & 10211.2 & 9.9 & 0.992 \\
& Pyr & 10372.7 & 9.8 & 0.771 \\
& PAH & 9330.2 & 9.5 & 0.942 \\
PS $+\mathrm{NaCl}$ & PhA & 5523.3 & 5.5 & 0.854 \\
& Flu & 4294.8 & 3.8 & 0.669 \\
& Pyr & 3077.5 & 2.7 & 0.590 \\
& PAH & 4135.8 & 4.2 & 0.737 \\
\hline
\end{tabular}

Note: (1) $\log K=-A / T+B ; K=\mathrm{PAH}_{(\mathrm{gas})} /\left(\mathrm{PAH}_{\text {(solid) }} /\right.$ particulates).

(2) $\mathrm{PAH}_{3}=\mathrm{PhA}+\mathrm{Flu}+\mathrm{Pyr}$.

(3) $R^{2}$, correlation coefficient.

temperature increased. When the stage-two incineration system was controlled at $900^{\circ} \mathrm{C}$ as were various oxygen supplies, the maximum value of $\log K$ occurred at $0.0525 \mathrm{O}_{2}(\mathrm{nl} / \mathrm{min})$ and $\log K$ value decreased as the oxygen supply increased, as shown in Fig. 5 and the constants $A$ and $B$ are given in Table 3.

From the results of the TA98 Ames test in Table 4, when PS was pyrolyzed from $700^{\circ} \mathrm{C}$ to $1200^{\circ} \mathrm{C}$, the mutagenicity was increased as the second-stage temperature increased, as shown in Fig. 6. The maximum mutagenicity of particulates extracts occurred at $1100^{\circ} \mathrm{C}$ and were about 3000 revs/plate with $\mathrm{BaCl}_{2}$ and $\mathrm{NaCl}$ additives. When the second-stage temperature increased to $1200^{\circ} \mathrm{C}$, the mutagenicity of the extracts decreased.

The mutagenicity of particulates and PUF extracts at the second-stage temperature of $900^{\circ} \mathrm{C}$ and various oxygen supplies are given in Table 5. When oxygen supply was increased from 0 to $0.210 \mathrm{nl} / \mathrm{min}$, the mutagenicity of particulates extracts from the PS incineration with metallic chloride additives was still more stronger. Thesc results were surprising and thcy were very different from the previous results from the incineration of polystyrene without metallic chloride additives [19]. Also, the correlations between mutagenicity and $\mathrm{PAH}_{7}(\mathrm{BaP}, \mathrm{BbF}, \mathrm{BaA}, \mathrm{IP}, \mathrm{DbA}$, Tri and $\mathrm{Chr}$ ) from polystyrene incineration with $\mathrm{BaCl}_{2}$ or $\mathrm{NaCl}$ additive at various operation conditions were not so good. The reason is that other toxic compounds (i.e., nitro-PAHs, dioxin and furan) might be formed and should be identified in future research work.

However, the mutagenicity of particulates and PUF extracts caused significantly higher potence of revertants to $S$. typhimurium TA98 in the presence of S9 mixture than that without S9 additive. This indicates that the emitted gas from the PS incineration contains not only direct-acting mutagens but also indirect mutagens, which 


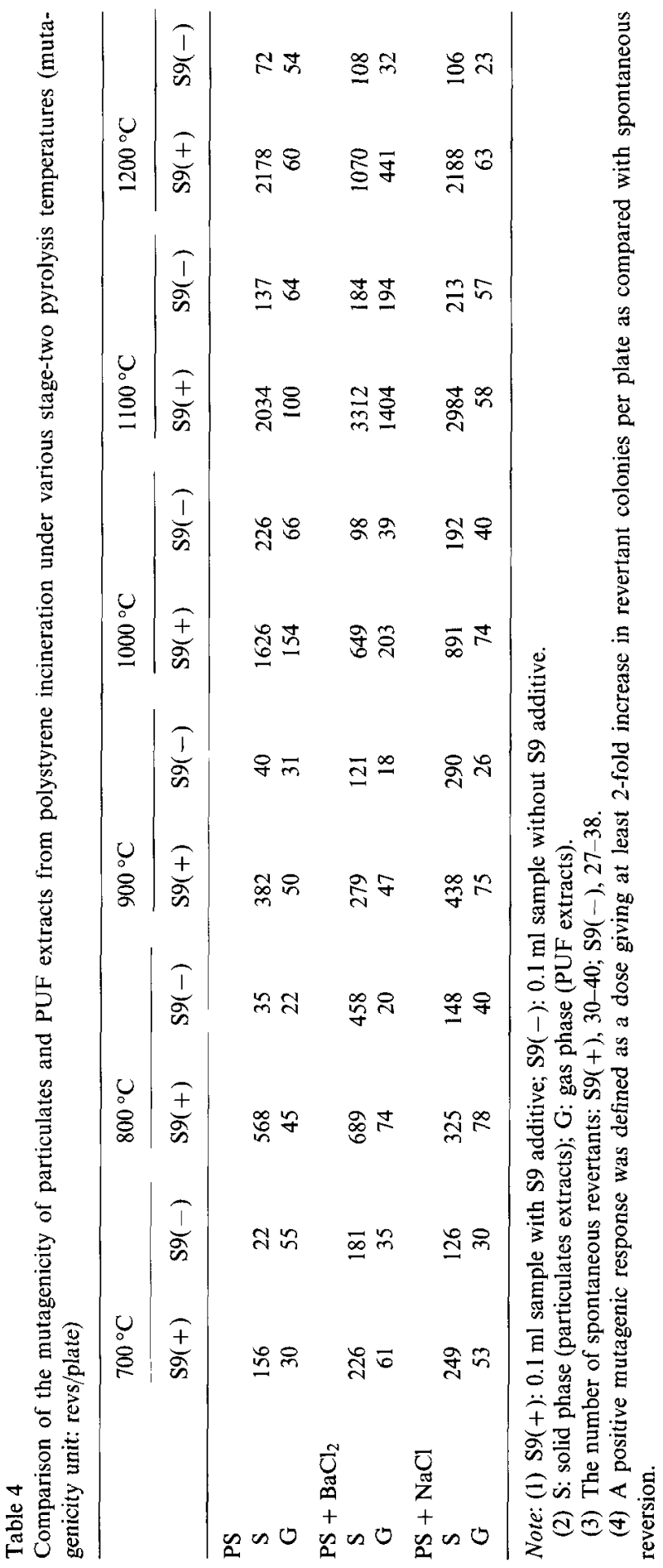


Table 5

Comparison of the mutagenicity of particulates and PUF extracts from polystyrene incineration under various oxygen supplies (mutagenicity unit: revs/plate)

\begin{tabular}{|c|c|c|c|c|c|c|c|c|}
\hline & \multicolumn{2}{|c|}{$0 \mathrm{nl} / \mathrm{min}$} & \multicolumn{2}{|c|}{$0.0525 \mathrm{nl} / \mathrm{min}$} & \multicolumn{2}{|c|}{$0.105 \mathrm{nl} / \mathrm{min}$} & \multicolumn{2}{|c|}{$0.210 \mathrm{nl} / \mathrm{min}$} \\
\hline & $\mathrm{S} 9(+)$ & $S 9(-)$ & S9(+) & $S 9(-)$ & $S 9(+)$ & $S 9(--)$ & $S 9(+)$ & $S 9(-)$ \\
\hline \multicolumn{9}{|l|}{ PS } \\
\hline S & 382 & 40 & 520 & 155 & 123 & 59 & 93 & 58 \\
\hline $\mathrm{G}$ & 50 & 31 & 125 & 60 & 95 & 57 & 94 & 24 \\
\hline \multicolumn{9}{|c|}{$\mathrm{PS}+\mathrm{BaCl}_{2}$} \\
\hline $\mathrm{S}$ & 279 & 121 & 636 & 207 & 254 & 107 & 1910 & 184 \\
\hline G & 47 & 18 & 72 & 31 & 76 & 26 & 129 & 36 \\
\hline \multicolumn{9}{|c|}{$\mathrm{PS}+\mathrm{NaCl}$} \\
\hline $\mathrm{S}$ & 438 & 257 & 344 & 322 & 691 & 377 & 527 & 70 \\
\hline $\mathrm{G}$ & 75 & 26 & 49 & 22 & 82 & 48 & 39 & 28 \\
\hline
\end{tabular}

Note: Same as Table 3.

are usually activated by the mixed-function oxygenases in the microsomes of animal liver to become ultimate mutagens whether the PS incineration system added metallic chloride or not. The mechanisms of epoxide formation and nucleophilic epoxide opening could be involved in metabolic oxidation. In the body, the epoxide ring should react with an amino group in celluar DNA to give an altered DNA that is covalently bound to the PAH. With its DNA thus altered, the cell was unable to reproduce normally. From the recent experimental results, sister chromatid exchanges in human lymphocytes were induced by the particulates extracts from polystyrene incineration, as shown in Fig. 7.

\section{Conclusions}

The critical temperature in the second-stage incinerator for the maximum yield of $14 \mathrm{PAHs}$ was shifted from $1000^{\circ} \mathrm{C}$ to $900^{\circ} \mathrm{C}$ when metallic chloride $\left(\mathrm{BaCl}_{2}\right.$ or $\left.\mathrm{NaCl}\right)$ was added to the incineration system. $\log K$ values, the ratios between the PAHs in gas phase and the PAHs in solid phases (per particulates weight; $1 / \mathrm{mg}$ ) increased as the stage-two pyrolysis temperature increased. When the second-stage furnace was controlled at $900^{\circ} \mathrm{C}$ and various oxygen supplies, the maximum value of $\log K$ occurred at $00525 \mathrm{O}_{2}(\mathrm{nl} / \mathrm{min})$.

Concerning the mutagenicity in the air emissions, the maximum mutagenicity of particulates and PUF extracts occurred at $1100^{\circ} \mathrm{C}$, when the pyrolysis temperature was increased from $700^{\circ} \mathrm{C}$ to $1200^{\circ} \mathrm{C}$. The mutagenicity of PUF extracts was weaker than the mutagenicity of particulates extracts. When oxygen supply was increased to $0.210 \mathrm{nl} / \mathrm{min}$ and stage-two temperature was controlled at $900^{\circ} \mathrm{C}$, the mutagenicity of particulates and PUF extracts were still higher for $\mathrm{NaCl}$ additive and were much higher for $\mathrm{BaCl}_{2}$ additive. Moreover, the mutagenicity is much higher in the presence of rat liver microsomal fraction ( $\mathrm{S} 9$ mixture) than that without $\mathrm{S} 9$ additive. 


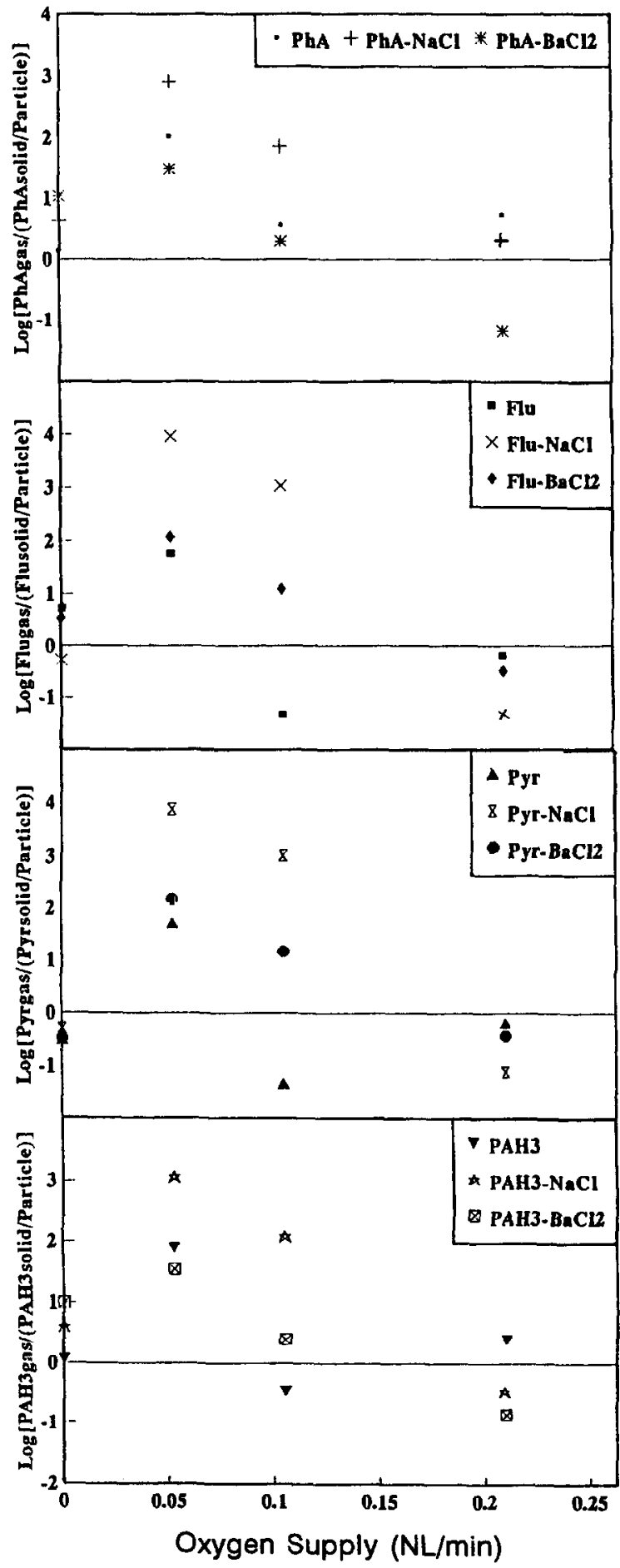

Fig. 5. The PAHs distributions between the solid and gas phases in air emissions from polystyrene incineration at $900^{\circ} \mathrm{C}$ and various oxygen supplies. 


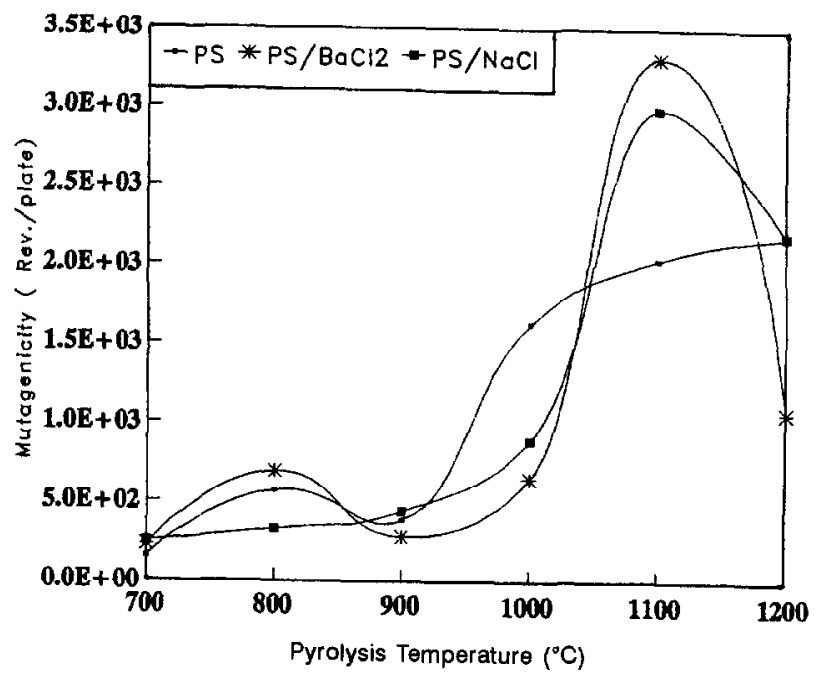

Fig. 6. The mutagenicity in air emissions from polystyrene incineration under various operation conditions.

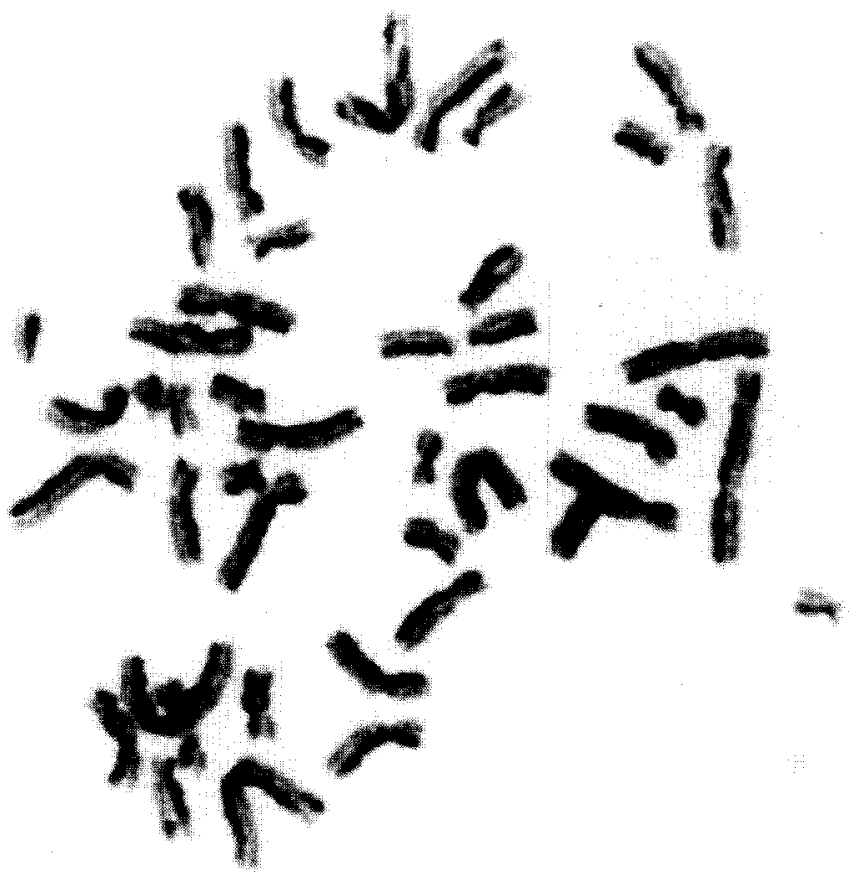

Fig. 7. Sister chromatid exchanges in human lymphocytes were induced by the particulates extracts from polystyrene incineration. 
Finally, from the results of this study, the metallic chloride in the municipal solid waste (MSW) should be considered as an important factor in design and operation of MSW incinerator. As for the toxic control and the risk assessment of human health, the SCE (sister chromatid exchange) test in the air emissions from various incineration conditions should also be taken into consideration and this should be worth researching in the future.

\section{References}

[1] J. Josephson, Environ. Sci. Technol., 18 (1984) 93.

[2] P.C. Chiang and J.H. You et al., Man and his Ecosystem, Proc. 8th World Clean Air Congress, Vol. 4, 1989, p. 289.

[3] O.I. Smith, Prog. Energy Combust. Sci., 7 (1981) 252.

[4] T.R. Hendersm, J.D. Sun, A.P. Li, R.L. Hansm and W.E. Bechtold, Environ. Sci. Technol., 18 (1984) 428.

[5] R. Panlman and O. Pelkonen, Carcinogenesis, 8 (1987) 773.

[6] T. Morikawa, J. Combust. Toxicol., 15 (1978) 347.

[7] T. Morikawa, Fire Sci. Technol., 4 (1984) 27.

[8] J.A. Mulholland, A.F. Sarofim, P. Sosothikul and A.L. Lafleur, Combust. Flame, 92 (1993) 161.

[9] B.S. Haynes and H.G. Wanger, Prog. Energy Combust. Sci., 7 (1981) 229.

[10] M. Frenklach, Combust. Sci. Technol., 74 (1990) 283.

[11] M. Frenklach and J. Warnatz, Combust. Sci Technol., 51 (1987) 265.

[12] M. Frenklach, D.W. Clary, T. Yuan and W.C. Gardiner, Cumbust. Sci. Technol., 50 (1986) 79.

[13] J.M. Smedley, A. Williams and K.D. Bartle, Combust. Flame, 91 (1992) 71.

[14] D.R. Thakker et al., in: P.W. Jones and P. Leber (Eds.), Polynuclear Aromatic Hydrocarbons, Proc. 3rd Int. Symp. on Chemistry and Biology-Carcinogenesis and Mutagenesis, Ann Arbor Science, Ann Arbor, 1979 , p. 455.

[15] J. Mcmurry, Fundamentals of Organic Chemistry, Brooks/Cole, Monterey, CA, 1986, p. 250.

[16] D.M. Demarini, R.W. Williams, E. Perry, P.M. Lemieux and W.P. Liank, Combust. Sci. Technol., 85 (1992) 437.

[17] D.M. Marron and B.N. Ames, Mutat. Res., 113 (1983) 173.

[18] B.N. Ames, J. McCann and E. Yamasaki, Mutat. Res., 31 (1975) 347.

[19] J.H. You, P.C. Chiang, K.T. Chang and S.C. Chang, J. Hazard. Mater., 36 (1994) 1. 